Article

\title{
Evaluation of Surface Characteristics and Cytotoxicity of Dental Composites
}

\author{
Antarinia Crăciun ${ }^{1}$, Ioana Bâldea ${ }^{2}$, Ana Ispas ${ }^{1}$, Mîndra Eugenia Badea ${ }^{3}$, Ioan Petean ${ }^{4}$, \\ Codruta Sarosi ${ }^{5, *(D)}$, Marioara Moldovan ${ }^{5}$, Stanca Cuc ${ }^{5}$, Razvan Ene ${ }^{6,7, *}$ and Maria Crişan ${ }^{8}$
}

1 Department of Prosthodontics and Dental Materials, Iuliu Haţieganu University of Medicine and Pharmacy, 32 Clinicilor St., 400006 Cluj-Napoca, Romania; craciun.antarinia@umfcluj.ro (A.C.); ispas.ana@umfcluj.ro (A.I.)

2 Department of Physiology, Iuliu Haţieganu University of Medicine and Pharmacy, 1 Clinicilor St., 400006 Cluj-Napoca, Romania; baldeaioana@gmail.com

3 Deparatment of Preventive Dental Medicine, Iuliu Haţieganu University of Medicine and Pharmacy, 31 AvramIancu St., 400083 Cluj-Napoca, Romania; mindrabadea@gmail.com

4 Faculty of Chemistry and Chemical Engineering, Babes-Bolyai University, 11 Arany Janos St., 400084 Cluj-Napoca, Romania; petean.ioan@gmail.com

5 Department of Polymer Composites, Babes-Bolyai University, Raluca Ripan Institute for Research in Chemistry, 30 Fantanele St., 400294 Cluj-Napoca, Romania; mmarioara2004@yahoo.com (M.M.); stancabobo@yahoo.com (S.C.)

614 Department, Orthopedics, Anesthesia and Intensive Care (AIC), University of Medicine and Pharmacy Carol Davila Bucharest, 8 Eroii Sanitari St., 050474 Bucharest, Romania

7 Orthopedics and Traumatology Department, Bucharest Emergency University Hospital, 169 Splaiul Independentei St., 050098 Bucharest, Romania

8 Department of Dermatology, Iuliu Hatieganu University of Medicine and Pharmacy, 1 Clinicilor St., 400006 Cluj-Napoca, Romania; mcrisan7@yahoo.com

* Correspondence: codruta.sarosi@gmail.com (C.S.); razvan77ene@yahoo.com (R.E.)

Received: 1 July 2020; Accepted: 28 July 2020; Published: 30 July 2020

\begin{abstract}
The purpose of this study was to evaluate the surface and in vitro cytotoxicity on human dysplastic oral keratinocytes (DOK) of four commercial resins-based dental composites commonly used in prosthodontics dental therapies: two indirect composites for crown and bridges-SR Adoro (IvoclarVivadent $\mathrm{GmbH}$ ) and Solidex (Shofu Dental $\mathrm{GmbH}$ ); and two dual-curing luting resin cements-RelyxUnicem (3M ESPE Dental Products) and Variolink Esthetic DC (IvoclarVivadentGmbH). A complex assessment of surface characteristics of the four materials was conducted before and after the exposure to artificial saliva through various analyses, such as Scanning Electron Microscopy, Atomic Force Microscopy and Cross Polarized Light Microscopy (PLM). The results showed that DOK viability was not severely affected by exposure to any of these materials; however, Variolink expressed higher values but still above the toxicity level of the rest of the composites. The analysis of the surface structure between initial and artificial saliva exposed specimens returned a compact aspect in both categories and although Variolink and Relyx were subjected to increased roughness after saliva exposure, no damage of the internal compactness was recorded, demonstrating a fair behavior of the luting cements in contact with the saliva.
\end{abstract}

Keywords: surface properties; surface topography; dental composites; cytotoxicity; AFM; SEM

\section{Introduction}

The engineering technology of dentistry resin-based composite materials is in continuous development. It is focused to meet the demanding biological, functional and esthetic requirements in 
the same material. These properties have been consolidated by their clinical performances and their composition. They were studied and improved over the last few decades [1].

The biocompatibility of these materials is one of the mandatory considerations for practitioners to choose along with the esthetic qualities and mechanical properties [2,3]. It depends on the stability of the composites in the humid oral environment. Over the years, immediate dentin sealing has been extensively studied, demonstrating how adhesive systems bind better to newly prepared dentin, thus protecting the dentin-pulp complex and increasing the adhesion strength. After the polymerization, an external layer, called the oxygen-inhibition layer (OIL) appeared not polymerize, which may affect the restoration [4]. In 2009 Magne and Nielsen studied the interactions between impression materials and immediate dentin sealing, and they concluded that the use of glycerin and air blocking followed by an additional light polymerization, significantly reduced the thickness of the OIL [5].Changes in the composition of resin-based materials may occur over time due to the interactions between their surface and saliva, bacterial plaque and food [6].

Resin-based prosthetic materials used in dentistry often have cytotoxic properties due to the incomplete polymerization [7,8]. The cytotoxicity of several resin-based materials has been reported in the literature in variable levels, cell culture studies being frequently used in the analysis of their composition, structure and elutes $[9,10]$.

Furthermore, the chemical and mechanical degradation of these materials plays a key role in the cytotoxic mechanism due to leading to the elution of residual monomers and other substances, such as initiators and activators. These eluted substances are dangerous in direct contact with living cells, as they all cause significant toxicity $[10,11]$. Cokic et al. studied the cytotoxic effects of composite dust on human bronchial epithelial cells and they observed that neither membrane damage nor release of IL-1 $\beta$ was detected over the complete concentration range. The metabolic activity gradually declined for concentrations higher than $660 \mu \mathrm{g} / \mathrm{mL}$, and the release of IL-6 was reduced when cells were exposed to the highest concentrations of dust [12]. Landuyt et al. concluded that abraded particle preparations from dental composites, which contain considerable amounts of nanoparticles, inferred virtually no cytotoxicity to cultured alveolar macrophages in vitro up to a cell burden of $60 \mathrm{pg} / \mathrm{cell}$ [13].

The resin based materials surface roughness influences both the wear phenomena [14] biofilm accumulation [15] as well as those of discoloration, staining and overall esthetics [16]. Significant modifications were made to the inorganic fillers of the composites in order to obtain a better wear resistance $[17,18]$. An important feature of the composite surface is the low roughness in direct relation with the degree of the surface gloss retention [19].

Taking into account the afore mentioned considerations, we decided to conduct an experimental study, in vitro, on human oral cells, on the biocompatibility and surface properties of four commercial dental composites, commonly used in prosthodontics dental therapies: two indirect composites for crown and bridges-SR Adoro (IvoclarVivadent GmbH, Wien, Austria) and Solidex (Shofu Dental $\mathrm{GmbH}$, Ratingen, Germany) and two dual-curing luting resin cements-RelyxUnicem (3M ESPE Dental Products, St. Paul, MO, USA) and Variolink Esthetic DC (IvoclarVivadent GmbH, Wien, Austria). The surface structure of these materials was investigated by scanning electron microscopy-SEM, atomic force microscopy-AFM, and cross polarized light microscopy-PLM. Biocompatibility testing of the compounds was performed in vitro on human Caucasian dysplastic oral keratinocytes (DOK), by the measurement of the cell viability. The null hypotheses to be tested were: (i) there would be no significant effect of material's type on surface modification, (ii) there would be no significant effect of storage medium of surface modification, and (iii) there would be no significant effect on the in vitro toxicity of commercial composites.

\section{Materials and Methods}

The dental composites investigated in present study are described in Table 1. The disk specimens (diameter $15.0 \pm 0.1 \mathrm{~mm}$, thickness $1.0 \pm 0.1 \mathrm{~mm}$ ) from each material, were cured in the Teflon mold with Woodpecker LED-B Curing Light lamp (Guilin Woodpecker Medical Instrument, Co. Ltd., Guilin, 
China) in 9 points about $20 \mathrm{~s} /$ point. The surface of specimens was investigated by AFM and SEM after immersion in artificial saliva for 44 days at $37 \pm 1^{\circ} \mathrm{C}$ in a water bath. Artificial saliva was obtained in the laboratory, simulating the salt composition of saliva, according to the following recipe: $0.4 \mathrm{~g} / \mathrm{L} \mathrm{KCl}$, $0.4 \mathrm{~g} / \mathrm{L} \mathrm{NaCl}, 0.69 \mathrm{~g} / \mathrm{L} \mathrm{NaH}{ }_{2} \mathrm{PO}_{4} \cdot \mathrm{H}_{2} \mathrm{O}, 0.005 \mathrm{~g} / \mathrm{N} \mathrm{Na}_{2} \mathrm{~S} \cdot 9 \mathrm{H}_{2} \mathrm{O}, 0.795 \mathrm{~g} / \mathrm{L} \mathrm{CaCl}_{2} \cdot 2 \mathrm{H}_{2} \mathrm{O} 1.0 \mathrm{~g} / \mathrm{L} \mathrm{CO}\left(\mathrm{NH}_{2}\right)_{2}$, aqueous solution [20].

Table 1. Materials investigated in this study.

\begin{tabular}{|c|c|c|c|c|}
\hline Material/Use & Manufacturer & Organic Matrix & Inorganic Filler & Ratio(\%) \\
\hline $\begin{array}{l}\text { SR Adoro light-/heat-curing } \\
\text { veneering composite for } \\
\text { full-coverage and partial } \\
\text { veneer, metal-supported and } \\
\text { metal-free restorations }\end{array}$ & $\begin{array}{l}\text { IvoclarVivadentGmbH, } \\
\text { Wien, Austria }\end{array}$ & UDMA & $\begin{array}{c}\text { Glass with } \mathrm{Ba}, \mathrm{SiO}_{2} \\
\text { Stabilizers, catalysts and } \\
\text { pigments }\end{array}$ & $48 / 51$ \\
\hline $\begin{array}{l}\text { Variolink Esthetic DC } \\
\text { Self-adhesive resin cement }\end{array}$ & $\begin{array}{l}\text { IvoclarVivadentGmbH, } \\
\text { Wien, Austria }\end{array}$ & $\begin{array}{l}\text { UDMA } \\
\text { and further methacrylate } \\
\text { monomers. }\end{array}$ & $\begin{array}{c}\text { Ytterbium trifluoride, } \\
\text { spheroid mixed oxide, } \\
\text { particle size } 0.04-0.2 \mu \mathrm{m} . \\
\text { (mean particle size: } 0.1 \mu \mathrm{m})\end{array}$ & $32 / 67$ \\
\hline $\begin{array}{l}\text { RelyxUnicem } \\
\text { Self-adhesive resin cement }\end{array}$ & $\begin{array}{l}\text { 3M ESPEDental } \\
\text { Products, St. Paul, } \\
\text { MO, USA }\end{array}$ & $\begin{array}{l}\text { Methacrylate monomers } \\
\text { containing phosphoric } \\
\text { acid groups, methacrylate } \\
\text { monomers }\end{array}$ & Silanated fillers & $30 / 70$ \\
\hline $\begin{array}{c}\text { Solidex } \\
\text { Composite for crowns and } \\
\text { bridges on metal frames }\end{array}$ & $\begin{array}{l}\text { ShofuDental GmbH, } \\
\text { Ratingen, Germany }\end{array}$ & UDMA & $\begin{array}{l}\text { Inorganic filler particle } \\
\text { range: } 0.16-7 \mu \mathrm{m}\end{array}$ & $47 / 53$ \\
\hline
\end{tabular}

\subsection{Cross Polarized Light Microscopy (PLM)}

The cross polarized light passes through the sample and interacts with the material. The amorphous areas will appear dark in the microscope eyepiece and the crystalline ones will have a certain color according to the mineral optical properties. Therefore, the materials discs were cut in a plan parallel manner to a thickness of about $40 \mu \mathrm{m}$ to assure a proper transmission of the polarized light beam trough the samples. Both surfaces of the discs were polished up to mirror quality. These were investigated using an optical mineralogic microscope with cross polarized light, Laboval 2 (Carl Zeiss Jena, Oberkochen, Germany), equipped with a 10-megapixel Kodak digital camera (Eastman Kodak, Rochester, NY, USA).

\subsection{Atomic Force Microscopy (AFM)}

The specimens for the AFM investigation were prepared in a similar manner to those used for the PLM microscopy. Surface morphology and roughness were investigated for each material by atomic force microscopy (JEOL JSPM 4210 Scanning Probe Microscope, Tokyo, Japan). The observation was performed in tapping mode assuring an optimal interaction between the cantilever tip and sample surface. The used cantilevers are NSC 15 (Micromasch Co., Sofia, Bulgaria) with the resonant frequency $325 \mathrm{kHz}$ and force constant $40 \mathrm{~N} / \mathrm{m}$. A scan rate of about $1 \mathrm{~Hz}$ was used to record the topographic images. At least 3 different macroscopic zones of each specimen were scanned to achieve a significant amount of representative data for the roughness measurement. They were scanned at a size of $5 \times 5 \mu \mathrm{m}$, which assures an optimal view of the fine microstructural level. The images were processed using WinSPM 2.0 Processing software powered by JEOL for the AFM microscopes. The processing software is used to measure the surface roughness and to perform profiles trough the topographic images.

\subsection{Scanning Electron Microscopy (SEM)}

The structure of specimen surfaces for each investigated material was carried out by electronic scanning microscopy (SEM-Inspect S, FEI, Hillsboro, OR, USA), with tan accelerating voltage between $200 \mathrm{~V}$ and $30 \mathrm{kV}$, functional in high-vacuum and low-vacuum. The analyzed images magnified by 500× 
and 1000x times were collected using CCD-IR infrared inspection camera and backscatter electron detector, with image processing up to $4096 \times 3536$ pixels.

\subsection{In Vitro Cytotoxicity}

\subsubsection{Cell Cultures}

The assays were performed on human Caucasian dysplastic oral keratinocytes DOK (ECCAC 94122104), purchased from Sigma-Aldrich Chemicals Company (Heidelberg, Germany), and used at their 32-33 passage (initial passage from producer-31). Cell culture medium was DMEM (Dubelco's modified Eagle's medium), supplemented with 5\% FBS (Foetal Bovine Serum), $5 \mu \mathrm{g} / \mathrm{mL}$ hydrocortisone, antibiotics, anti-mycotics; all reagents were purchased from Sigma-Aldrich, Co (Heidelberg, Germany).

\subsubsection{Sample Extract Preparation}

Samples of each dental material were washed in $70 \%$ ethanol for $1 \mathrm{~min}$, and then rinsed three times in sterile PBS to remove any residual substances and/or bacteria from the material surface. The samples were then incubated with medium, at a concentration of $3 \mathrm{~cm}^{2} / \mathrm{mL}$, complying with the ISO 10993-12:2012 [21] proceedings, at $37^{\circ} \mathrm{C}$ for $24 \mathrm{~h}$. The obtained extract was used immediately for the experiments.

\subsubsection{Viability Assay}

Cell survival was assessed through the colorimetric measurement of formazan, a colored compound synthesized by viable cells, using CellTiter $96^{\circledR}$ AQueous Non-Radioactive Cell Proliferation Assay (Promega Corporation, Madison, USA). The cells were cultivated at a density of $10^{4} /$ wells in 96 wells plaques (TPP, Trasadingen, Switzerland) for $24 \mathrm{~h}$, then exposed to the sample extracts diluted with medium $(1=$ undiluted; $0.5=$ diluted $1: 1 ; 0.25=$ diluted $1: 3)$ for $24 \mathrm{~h}$. Viability was measured colorimetrically, using an ELISA plate reader (Tecan, Männedorf, Switzerland) at $540 \mathrm{~nm}$. All the experiments were done in triplicate. Untreated cell cultures were used as controls. Results are presented as $\mathrm{a} \%$ of untreated control, the dose that caused a viability decrease below $70 \%$ was considered toxic.

\subsubsection{Statistical Analysis}

The statistical differences between experimental materials and control groups were evaluated by two way ANOVA, followed by the Bonferoni posttest; all the values in text and figures are expressed as mean \pm standard deviation; results were considered significant for $p \leq 0.05$. Statistical package used for data analysis was Prism version 4.00 for Windows, GraphPad Software, San Diego, CA, USA.

\section{Results}

\subsection{Cross Polarized Light Microscopy}

The dental composites in the present paper are complex systems having crystalline particulate matter filler. The amount of crystal phase is beyond of the detection limit affordable for $\mathrm{X}$ ray diffraction (XRD) in each of the samples. Therefore, XRD spectroscopy is not suitable for our specimens. PLM was the proper choice under the circumstances. It was used to observe the distribution of the crystal phase into the dental composites.

The polarized light passes through the samples and features dark areas for the amorphous material and bright shiny spots for the crystal phase. The obtained images are displayed in Figure 1. 

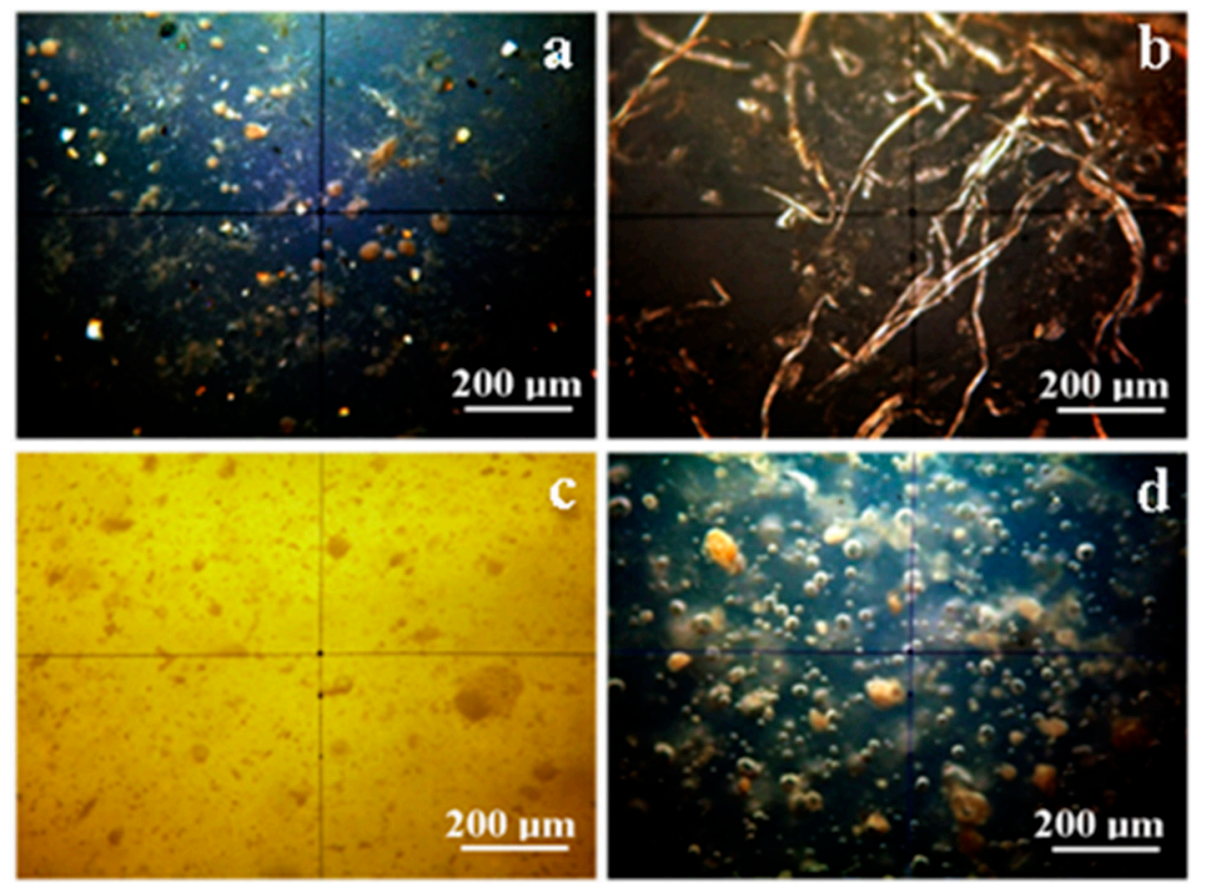

Figure 1. PLM images of the thin slices of the samples: (a) Adoro; (b) Variolink; (c) Relyx and (d) Solidex.

Adoro, Figure 1a, presents a complex crystal structure with three distinct categories well spread among the amorphous polymer. The first crystal category is formed by rounded particles having a diameter in the range of 10 to $40 \mu \mathrm{m}$ with brown nuance. They are related to the clusters of fine pigments in the composition of Adoro material. The second crystal category is formed by particles with a rocky shape colored in nuance ranging from green gray to bright white. It is correlated with $\mathrm{SiO}_{2}$ found in the composite. The third crystal category is a brown-grey shallow (in brighter spots the shallow tends to a light yellow nuance) mixed up with the other crystal phases and with the amorphous material. The observed distribution and chromatic nuance of the third crystal category show us that it is a very fine distribution of the pigment in the polymer mass.

The Variolink sample has a uniform amorphous structure with lesser details in cross polarized light. A brown shallow with low light intensity is observed. It perfectly correlates with the fines dispersion of Ytterbium trifluoride, spheroid mixed oxide. Their appearance deals with an average particle size of about $100 \mathrm{~nm}$ given by the producer. Still, there are found some spots with fiber-like formations with evidenced in the Figure $1 \mathrm{~b}$. Their nuance is light brown to light yellow and have a $400-800 \mu \mathrm{m}$ length and 5-15 $\mu \mathrm{m}$ diameter. These rare spots observed in Variolink are related to the some local concentrations of the crystalline component.

Relyx, Figure 1c, has a very interesting structure because of its different kind of distribution of the crystalline matters. The image nuance is light yellow, which means that the crystal phase is extremely well dispersed among the amorphous polymer giving the uniform light nuance. Its aspect is explained by the silanated fillers from the composition. Data in literature show such fine particulate dispersions as with $\mathrm{TiO}_{2}$ nano-particles observed by high resolution SEM imaging [1,2]. In our case, the silanated filler could be nano-structured in a similar manner and to be well dispersed into the polymer phase. Therefore, high-resolution SEM and AFM are required for the proper surface characterization of the material $[22,23]$.

Rounded particles with a diameter between 5-50 $\mu \mathrm{m}$ are seen in the Relyx composition. These particles have a lower crystalline state then the potential nanostructured silanized filler. They could be local areas in the polymer with lower content of silanized filler. It results in a local less intense nuance of the image. 
Solidex, Figure 1d, feature a lot of gas bubbles (5 to $20 \mu \mathrm{m}$ diameter), well dispersed into the polymer volume. The crystal compounds are very similar to the ones observed in the Adoro sample.

The rounded particles with brown nuance have diameters between 10 to $60 \mu \mathrm{m}$. They are very similar to the pigment clusters observed in Adoro. Thus, similar pigments and additives may have been used in Solidex. The second crystal category of Solidex is the brown-grayish shallow mixed onto the polymer. It could be a local nano-structured dispersion of the inorganic filler mentioned in product data sheet. A major difference in Solidex compared to Adoro is the lack of bright white particles. This is normal, because Solidex do not report silica as a component in the data sheet.

\subsection{Scanning Electron Microscopy (SEM) Analyses}

The cross polarized light microscopy gives a look inside of the materials. The exterior aspect was investigated with SEM microscopy, which reveals the shape of the surfaces. Thus, all samples were investigated by SEM microscopy. The obtained images are displayed in Figure 2.

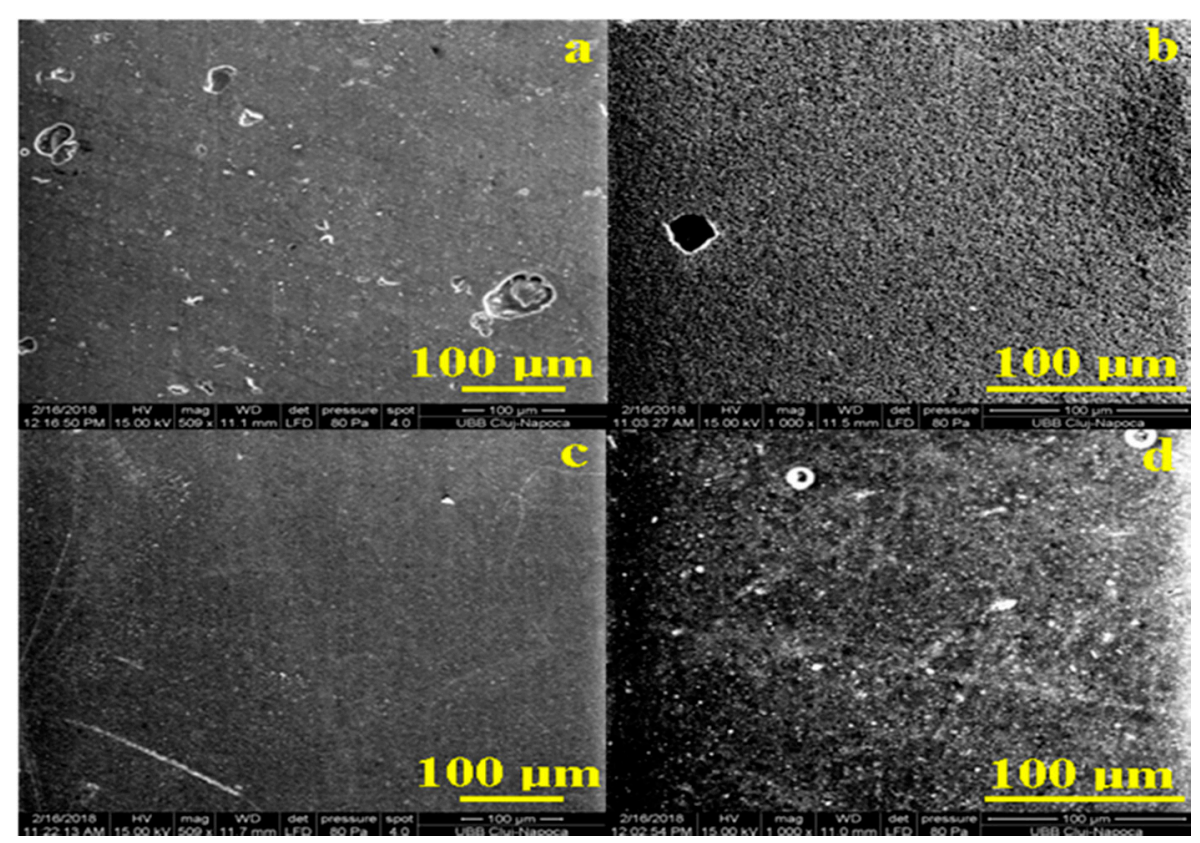

Figure 2. SEM images of the initial samples: (a) Adoro, (b) Variolink, (c) Relyx, and (d) Solidex captured with $500 \times$ and $1000 \times$ magnitude.

It results that all initial samples have a compact and uniform surface at large micro-scale observation. The compaction of the components gives resistance to the material at liquids penetration. The most compact and uniform surface is identified for Relyx followed by Adoro, and the last are Variolink and Solidex. The irregularities of the surface are caused mainly by gas bubbles trapped into the polymer which reach the top. Solidex has a significant number of such bubbles but with diameters below $30 \mu \mathrm{m}$, in good agreement with optical observation; Figure 2d. Adoro features a smaller number of irregularities with diameters below $20 \mu \mathrm{m}$ and Variolink features rare irregularities but of relative greater diameters of about $40 \mu \mathrm{m}$ and in some places on the surface could be observed some ditches; Figure 2a,b. Relyx has no irregularity.

Exposure to artificial saliva may affect the surface of the samples. The SEM images obtained for exposed samples are presented in Figure 3a,b. The integrity and compaction of the surface remains unchanged for Adoro and Solidex, but the irregularities are more visible. The explanation is the local loss of crystalline material at the top bubbles margins. On the other hand, Variolink and Relyx show a still compact surface but with a blurred structure. Blurring of the materials structure in the surface indicates the possibility that saliva conducts to a wet erosion of the material. Such changes are better observed by AFM investigation. 


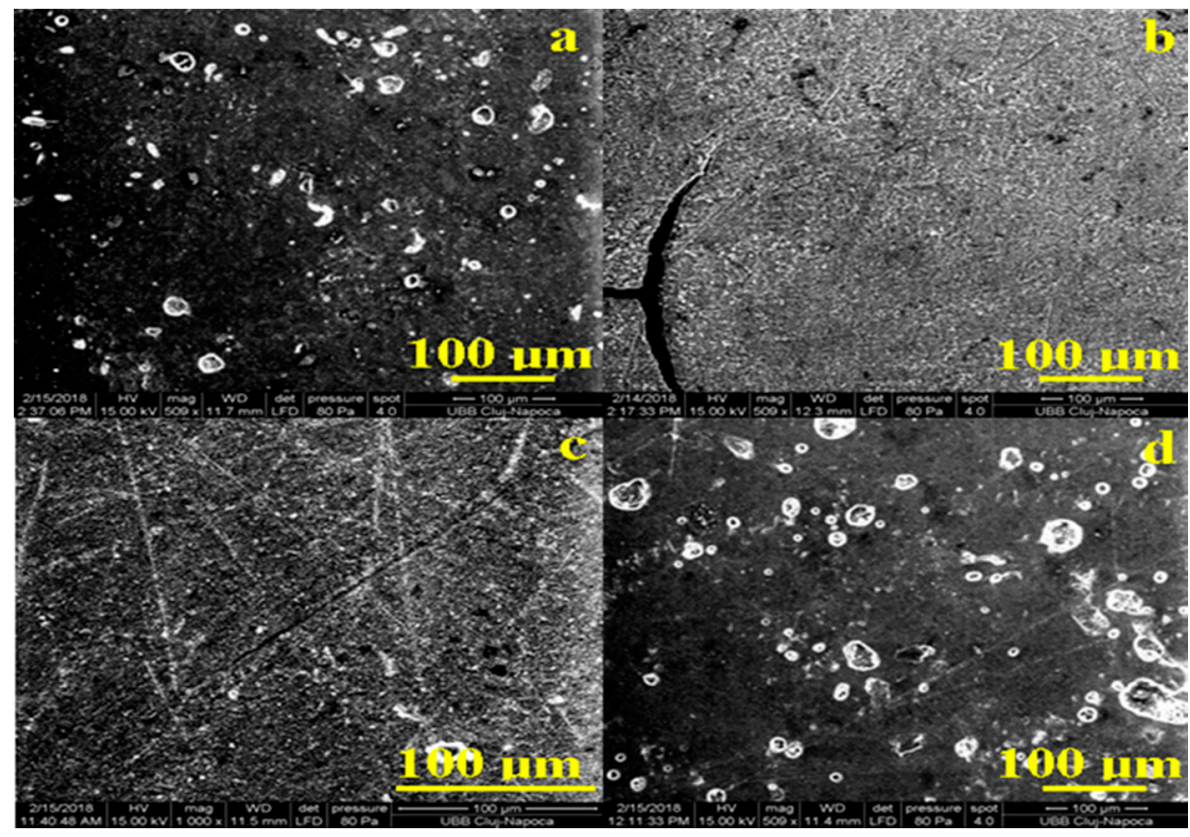

Figure 3. SEM images of the samples exposed 44 days to artificial saliva: (a) Adoro, (b) Variolink, (c) Relyx, and (d) Solidex captured with 500× and 1000× magnitude.

\subsection{Atomic Force Microscopy (AFM)}

The atomic force microscopy (AFM) is able to investigate the sample surface at high resolution at the fine micro-structural and to the nanostructure level. Therefore, the samples in the present study were investigated as initial state and after being exposed to the saliva. Any changes that could occur into the materials surface will be detected by the AFM cantilever. Figure 4 shows the AFM topographic images for the initial samples.

Adoro presents a well-structured and compact surface which features nano particles having the average diameter of about $75 \mathrm{~nm}$. It proves that the brown-gray shallow is the nano-dispersion of the fine pigment dispersion observed in PLM. The roughness values in Table 2 prove that the Adoro surface is uniform and smooth, and the profile reveals that the nano-particles are very well attached on the composite. It gives mechanical resistance and strength to fight against wet erosion.

Table 2. Values measured with AFM for the initial samples.

\begin{tabular}{ccccc}
\hline Material & Adoro & Variolink & Relyx & Solidex \\
\hline $\mathrm{Ra}, \mathrm{nm}$ & 22.9 & 89.9 & 11.9 & 24.0 \\
$\mathrm{Rq}, \mathrm{nm}$ & 31.8 & 115.0 & 15.3 & 29.9 \\
Diameter, $\mathrm{nm}$ & 75 & 80 & 40 & 60 \\
\hline
\end{tabular}

Variolink surface, Figure $4 \mathrm{~b}$, is also very compact and well organized. It seems that there is no filling material, only the polymer crystallites are observed into the structure. The topography reveals a good cohesion of Variolink crystallites having an average diameter of $80 \mathrm{~nm}$ and rounded shapes in a good agreement with the information in the data sheet. On the left side of the horizontal median of the image appears an $850 \mathrm{~nm}$ submicron cluster containing very well attached crystallites. The presence of such submicron clusters affects the surface roughness, which is significantly increased compared to the other samples.

Relyx surface, Figure 4c, evidences a very compact structure which contains small nano-particles of silanated filler with an average diameter of about $40 \mathrm{~nm}$. These are the finest nano-particles found in the investigated materials. This fine dispersion of the nano-particles in whole Relyx explains the uniform light yellow nuance observed in cross polarized light. The surface roughness is the lowest 
among the investigated samples. It is due to the finest nano-particles dispersion related to the high compaction of the material.
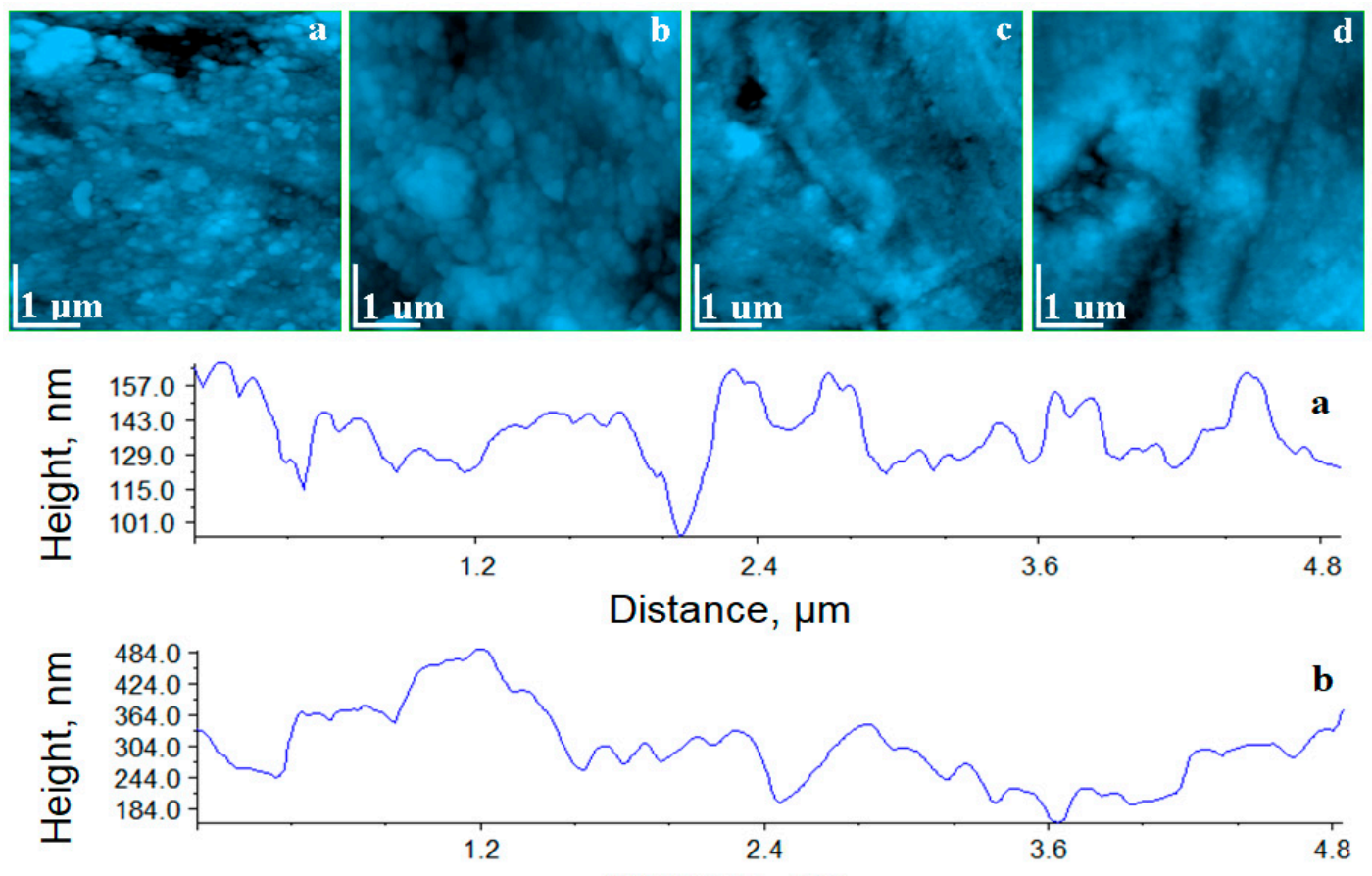

Distance, $\mu \mathrm{m}$
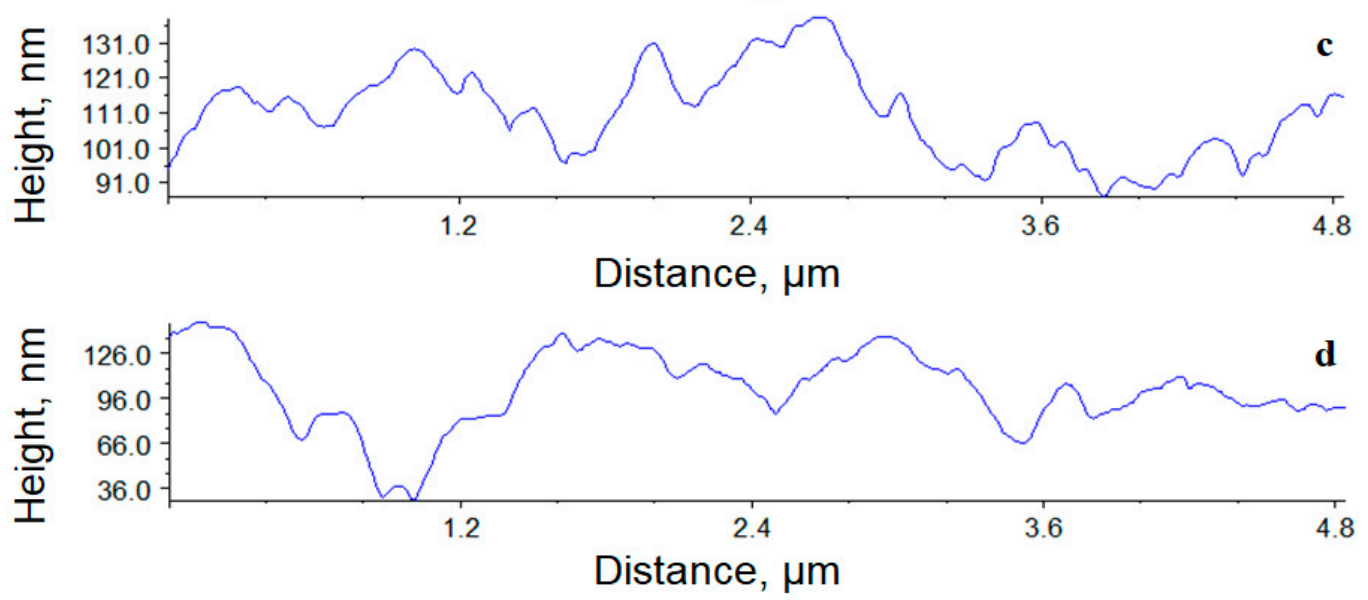

Figure 4. AFM topographic images for the reference samples: (a) Adoro, (b) Variolink, (c) Relyx, and (d) Solidex. Profiles on the horizontal median of each image are provided.

Solidex, Figure $4 \mathrm{~d}$, shows that the polymer surrounds the nano-particles in a very uniform manner and stacks them into a very compact structure. It is good for the material resistance in contact with liquids. The nanoparticles in Solidex have the same shape as those observed in Adoro, but their average diameter is significant smaller (e.g., $60 \mathrm{~nm}$ ). The correspondent profile evidences a smoother surface than the one observed for Adoro. Thus, the roughness of Solidex is about $29.9 \mathrm{~nm}$, situated between Relyx and Adoro.

AFM images prove that all initial samples assure a surface with a proper compactness to fit the dental application for which they were designed. Their resistance at in vivo conditions was tested in vitro using artificial saliva. The exposure effect on the samples surface was also investigated by AFM. The samples after exposure were cleaned with ultrapure water and dried and after were investigated by AFM. The resultant images are presented in Figure 5. 

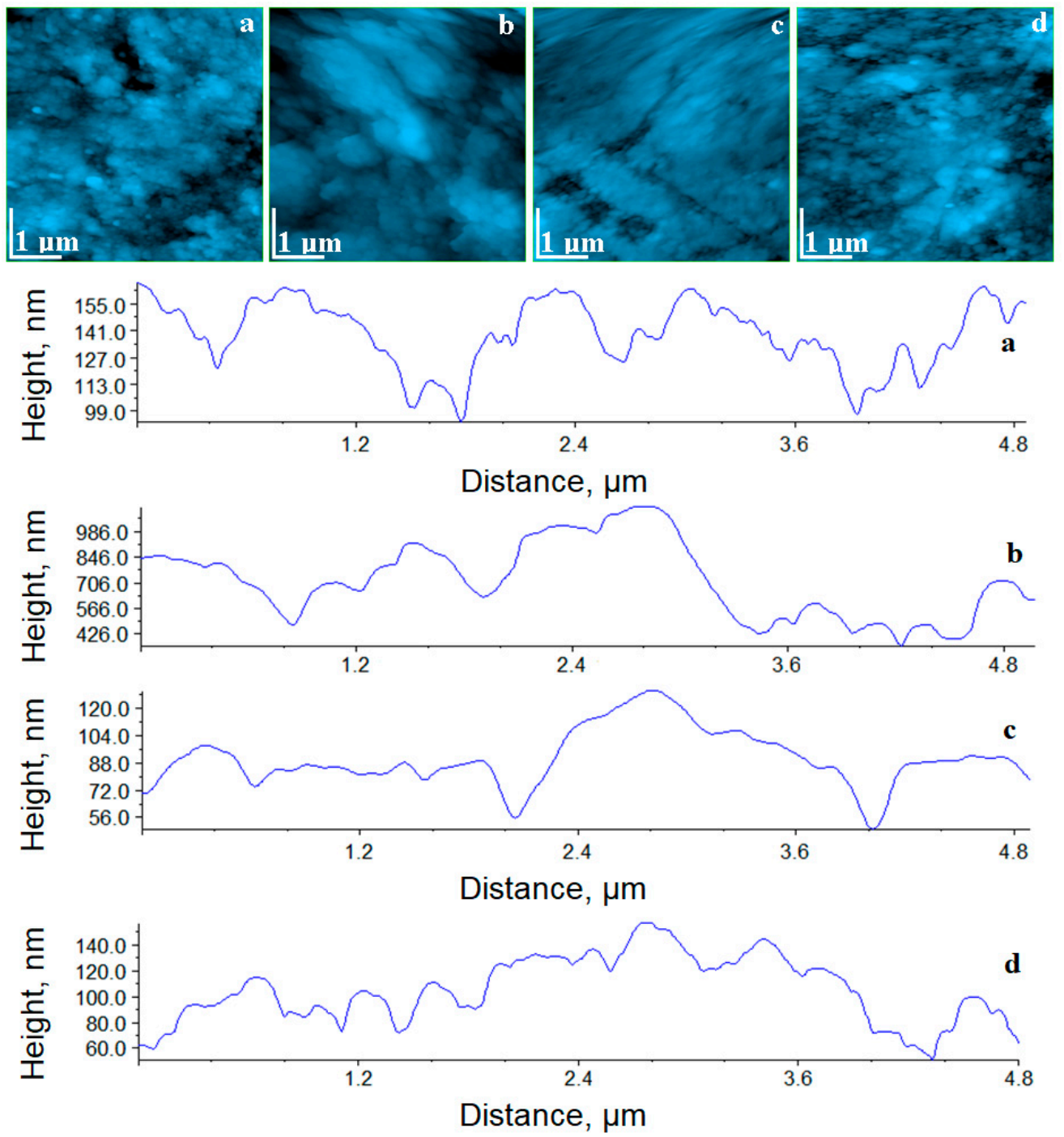

Figure 5. AFM topographic images for the samples exposed to saliva: (a) Adoro, (b) Variolink, (c) Relyx, and (d) Solidex. Profiles on the horizontal median of each image are provided.

The topography of Adoro and Solidex samples shows an unchanged surface. The compactness, surface roughness and nano-particle diameter are the same as those observed for the initial samples; see Table 3. This means that Adoro and Solidex have the best behavior at the contact with saliva.

Table 3. Values measured with AFM for the samples exposed to saliva.

\begin{tabular}{ccccc}
\hline Material & Adoro & Variolink & Relyx & Solidex \\
\hline $\mathrm{Ra}, \mathrm{nm}$ & 23.9 & 163.0 & 16.1 & 23.4 \\
$\mathrm{Rq}, \mathrm{nm}$ & 29.5 & 201.0 & 20.2 & 29.0 \\
Diameter, $\mathrm{nm}$ & 75 & 90 & 55 & 60 \\
\hline
\end{tabular}

The Variolink and Relyx surfaces present local alteration of the topography with traces of wet erosion, which leads to a significant increase in the surface roughness and of the nano-particles diameter. The good point is that no in depth erosion was observed, so the internal structure and compactness was not affected. The local erosions are only at the top of the surface. It proves that Variolink displays a good behavior, and Relyx displays a fair behavior, at the contact with the saliva. 


\subsection{In Vitro Cytotoxicity}

The data show that the dysplastic oral keratinocytes (DOK) viability was not severely affected by exposure to any of these dental materials, the $\%$ of viability was above $70 \%$ in all cases; therefore, none of these materials showed toxicity against DOK cells in our experimental setting; Figure 6.
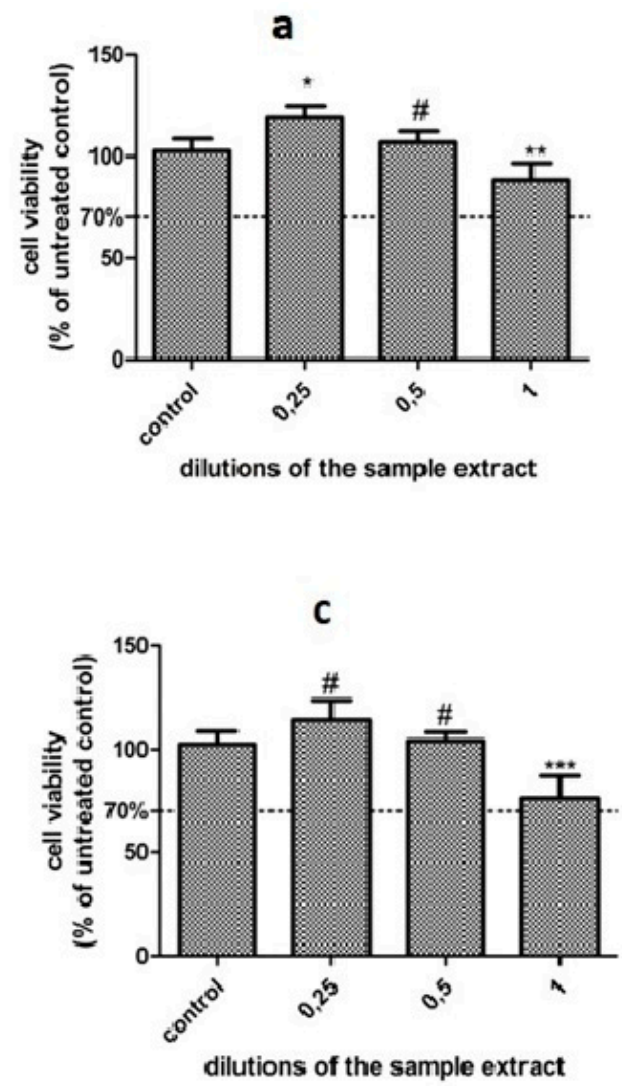
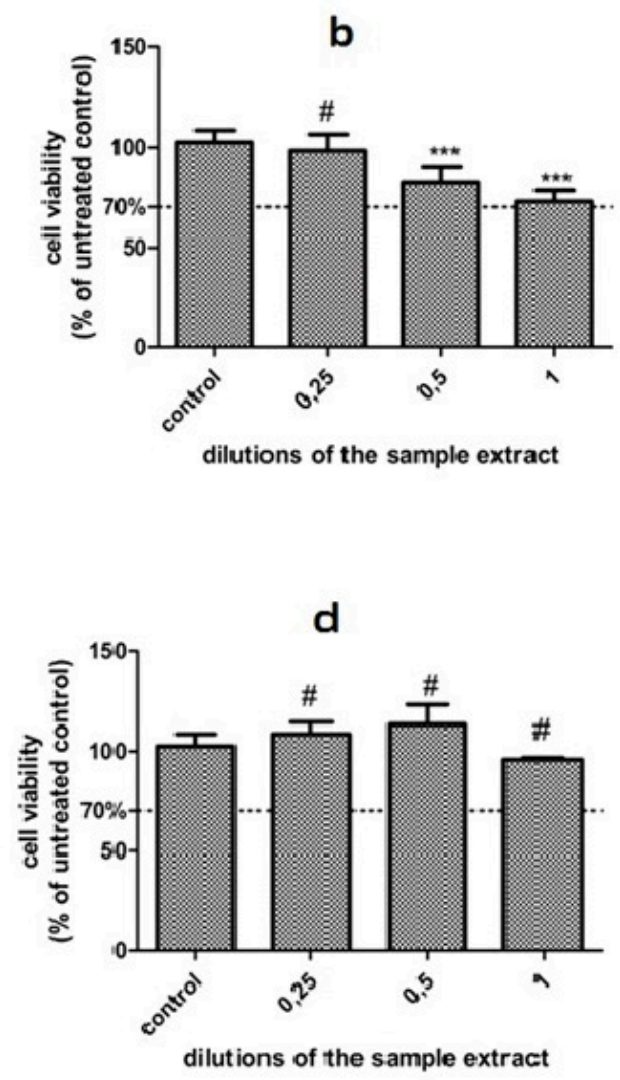

Figure 6. Cell viability of the DOK cultures exposed to the dental materials extracts for $24 \mathrm{~h}$; (a) Adoro, (b) Variolink, (c) Relyx, and (d) Solidex. Results are presented as \% of untreated control (mean \pm SD, $n=3)$; \# not significant, ${ }^{*} p<0.05 ;{ }^{* *} p<0.01$, ${ }^{* * *} p<0.001$, compared to control.

Overall, the Two Way Anova test showed a significant interaction between the cells treated with the different samples $(p<0.0001)$, while the concentration had also a significant impact $(p=0.0015)$.

There are some differences between the samples, as shown by the Bonferroni posttest. Solidex and Adoro seem to have a lower impact on DOK viability. When used in a smaller concentration (up to 50\%), they exhibited an increase in cell viability, probably through increased cell proliferation, while the undiluted sample slightly decreased viability (Solidex, $p=0.0063$, viability $>95 \%$ ); (Adoro, $p=0.0699$, viability $>85 \%$ ). Relyx induced a similar effect to Adoro; however, the undiluted samples diminished the viability more, $p=0.035$, viability $>76 \%$. Compared to the other samples, Variolink induced a stronger, dose-dependent decrease in cell viability, the undiluted sample extract diminished viability at $72 \%, p=0.0063$, but still above the toxicity level.

\section{Discussion}

The surface structure of the composites, as well as their wear resistance, depends on the type and percentage of filler content [24-27]. In our study, both the two microfilled (Adoro and Variolink) and two hybrid (Solidex and Relyx) resin-based materials shown in SEM analysis are compact structures. We also have to take into account the fact that further wear also produces surface changes; degradation being reported to affect more the layer below the matrix [28]. When resins are abraded, the resin matrix surrounding filler particles is the first component susceptible to be worn out; this process being 
responsible for the protrusion of fillers on the composite surface altogether with the apparition of bumps [29].

Significant differences among Ra values of each composite tested after artificial saliva immersion do not exist, the null hypothesis was rejected. Therefore, the surface modification after immersion in artificial saliva exists, so this null hypothesis was rejected.

Previous studies show that, throughout mechanical wear, lower surface roughness and higher gloss is achieved by composites with smaller particle sizes [30-32], and rougher surface by larger size or more irregular shaped filler particles [31,33-35], micro-roughness being correlated with gloss values [36].

AFM has also been conducted in the present study because this analysis provides a better and more detailed characterization of the surface roughness when compared with SEM. Regarding resin based composites, apart from the elution of various unreacted monomers and in strong relation with surface roughness [37-40] is the accumulation of bacteria, the maximum accepted threshold for dealing with plaque retention being $200 \mathrm{~nm}$ [41]. Another important factor is the matrix/filler interface chemically bond through a bifunctional organosilane [42,43] and if this link is weak microcracks, pits and craters can form and produce roughened and degradation of the resin surface [44-46]. This silane bond is at the same time susceptible to hydrolysis, which leads to polymer particle loss $[47,48]$ contributing to the alteration of the resin surface. This degradation is increased by the elution of several filler components, residual monomers and additives [6,49]. The process of light-induced polymerization is energy dependent and basically a product of light intensity and time [9]. In our study, the polymerization was achieved in 9 points, and could be considered a crucial factor in obtaining good clinical performance of dental composites.

As shown in our SEM and AFM analysis, although Variolink and Relyx exposed to saliva demonstrate similar compact surface as Adoro and Solidex, these specimens exhibit a significant increase in the surface roughness and of the nanoparticles' diameter due to a local alteration of the topography with traces of wet erosion. This behavior was also mentioned by previous studies, as polymer networks in a humid environment suffer from water sorption that leads to swelling, plasticization and softening of the composites [44,50].

Adoro and Solidex have not only shown the best behavior at the contact with the saliva, but they also had a lower impact on DOK viability compared to Variolink, and this finding can be correlated with the aforementioned increase in surface roughness found when these samples were exposed to artificial saliva.

In depth analysis of surface roughness, influenced by the resin matrix, the filler and the silane bond, and also a thorough understanding of the circumstances under which it appears and increases, could help improve future development of resin-based materials.

In vitro studies have a major impact on dental aesthetics, and surface characterization is important in clinical practice, which helps to choose an optimal material.

No "ideal" material has been developed until now, so clinicians should be aware of the performance and limitations of the materials used in order to achieve the desired outcomes. Study of the physical-chemical properties of the final products, such as surface roughness, rheological behavior, surface properties and cytotoxicity, can reduce limitations.

Nowadays, composites are the material of choice for direct restorations on posterior and anterior teeth, due mainly to their aesthetic properties, appropriate degradation properties, and low cytotoxicity.

However, these materials still have substantial limitations (e.g., polymerization shrinkage, coloring in time etc.), which may cause stress and jeopardize the integrity of the tooth/restoration interface. Some of the limitations of our study would be staining over time and shrinkage on polymerization. One limitation due to the size of the study is that the emphasis was on characterizing the surfaces of composites after aging in artificial saliva. 


\section{Conclusions}

The dental composites in the present paper are complex systems having crystalline particulate matter filler. The amount of crystal phase is beyond of the detection limit of affordable for the $\mathrm{X}$ ray diffraction (XRD) in each of the samples.

The analysis of the surface structure between initial and saliva exposed specimens returned a compact aspect in both categories, and although Variolink and Relyx were subjected to increased roughness after saliva exposure, no damage of the internal compactness was recorded, demonstrating a fair behavior of the luting cements in contact with the saliva.

AFM images prove that all initial samples assure a surface with a proper compactness to fits the dental application for which was designed. Significant differences among the Ra values of each composite tested after artificial saliva immersion do not exist.

The results showed that DOK viability was not severely affected by exposure to any of these materials; however, Variolink expressed higher values but still above the toxicity level of the rest of the composites.

For a better performance in clinical practice, in the future more long-term in vitro and in vivo studies are needed, with a greater variety of dental composites.

Author Contributions: Conceptualization, A.C. and M.C.; methodology, M.M.; validation, M.M., I.B. and M.C.; formal analysis, A.I.; investigation, I.B., C.S., I.P., S.C.; data curation, R.E.; writing-original draft preparation, A.C.; writing-review and editing, I.P. and C.S.; supervision, M.E.B. All authors have read and agreed to the published version of the manuscript.

Funding: This study was funded by the University of Medicine and Pharmacy IuliuHatieganu, Cluj-Napoca, through the PCD 7690/32/15.04.2016 grant.

Conflicts of Interest: The authors declare no conflict of interest.

\section{References}

1. Ferracane, J.L. Resin composite-State of the art. Dent. Mater. 2011, 27, 29-38. [CrossRef] [PubMed]

2. Hanks, C.T.; Wataha, J.C.; Sun, Z. In vitro models of biocompatibility: A review. Dent. Mater. 1996, 12, 186-193. [CrossRef]

3. Furtos, G.; Baldea, B.; Silaghi-Dumitrescu, L.; Moldovan, M.; Prejmerean, C.; Nica, L. Influence of inorganic filler content on the radiopacity of dental resin cements. Dent. Mater. 2012, 31, 266-272. [CrossRef] [PubMed]

4. Sinjari, B.; D’Addazio, G.; Murmura, G.; Di Vincenzo, G.; Semenza, M.; Caputi, S.; Traini, T. Avoidance of interaction between impression materials and tooth surface treated for immediate dentin sealing: An in vitro study. Materials 2019, 12, 3454. [CrossRef] [PubMed]

5. Magne, P.; Nielsen, B. Interactions between impression materials and immediate dentin sealing. J. Prosthet. Dent. 2009, 102, 298-305. [CrossRef]

6. Issa, Y.; Watts, D.C.; Brunton, P.A.; Waters, C.M.; Duxbury, A.J. Resin composite monomers alter MTT and LDH activity of human gingival fibroblasts in vitro. Dent. Mater. 2004, 20, 12-20. [CrossRef]

7. Cao, T.; Saw, T.Y.; Heng, B.C.; Liu, H.; Yap, A.U.J.; Ng, M.L. Comparison of different test models for the assessment of cytotoxicity of composite resins. J. Appl. Toxicol. 2005, 25, 101-108. [CrossRef] [PubMed]

8. Kaisarly, D.; El Gezawi, M. Polymerization shrinkage assessment of dental resin composites: A literature review. Odontology 2016, 104, 257-270. [CrossRef] [PubMed]

9. Geurtsen, W.; Lehmann, F.; Spahl, W.; Leyhausen, G. Cytotoxicity of 35 dental resin composite monomers in permanent 3T3 and three human primary fibroblast cultures. J. Biomed. Mater. Res. 1998, 41, 474-480. [CrossRef]

10. Vallittu, P.K.; Ekstrand, K. In vitro cytotoxicity of fibre-polymethyl methacrylate composite used in dentures. J. Oral Rehabil. 1999, 26, 666-671. [CrossRef]

11. Moldovan, M.; Balazsi, R.; Soanca, A.; Roman, A.; Sarosi, C.; Prodan, D.; Vlassa, M.; Cojocaru, I.; Saceleanu, V.; Cristescu, I. Evaluation of the degree of conversion, residual monomers and mechanical properties of some light-cured dental resin composites. Materials 2019, 12, 2109. [CrossRef] [PubMed] 
12. Cokic, S.M.; Hoet, P.; Godderis, L.; Wiemann, M.; Asbach, C.; Reichl, F.X.; De Munck, J.; Van Meerbeek, B.; Van Landuyt, K.L. Cytotoxic effects of composite dust on human bronchial epithelial cells. Dent. Mater. 2016, 32, 1482-1489. [CrossRef] [PubMed]

13. Van Landuyt, K.L.; Cokic, S.M.; Asbach, C.; Hoet, P.; Godderis, L.; Reichl, F.X.; Van Meerbeek, B.; Vennemann, A.; Wiemann, M. Interaction of rat alveolar macrophageswith dental composite dust. Part. Fibre Toxicol. 2016, 13, 62. [CrossRef]

14. Kakuta, K.; Wonglamsam, A.; Goto, S.; Ogura, H. Surface textures of composite resins after combined wear test simulating both occlusal wear and brushing wear. Dent. Mater. J. 2012, 31, 61-67. [CrossRef] [PubMed]

15. Cazzaniga, G.; Ottobelli, M.; Ionescu, A.; Garcia-Godoy, F.; Brambilla, E. Surface properties of resin-based composite materials and biofilm formation: A review of the current literature. Am. J. Dent. 2015, 28, 311-320.

16. Furuse, A.Y.; Gordon, K.; Rodrigues, F.P.; Silikas, N.; Watts, D.C. Colour-stability and gloss-retention of silorane and dimethacrylate composites with accelerated aging. J. Dent. 2008, 36, 945-952. [CrossRef]

17. Lu, H.; Lee, Y.K.; Oguri, M.; Powers, J.M. Properties of a dental resin composite with a spherical inorganic filler. Op. Dent. 2006, 31, 734-740. [CrossRef]

18. Tamas, C.; Moldovan, M.; Prejmerean, C.; Colceriu, A.; Furtos, G.; Vezsenyi, L.; Prodan, D.; Grecu, R.; Simon, V. Structure and properties of inorganic fillers for dental composites. J. Optoelectron. Adv. Mater. 2005, 7, 2849-2852.

19. O'Neill, C.; Kreplak, L.; Rueggeberg, F.A.; Labrie, D.; Shimokawa, C.A.K.; Price, R.B. Effect of tooth brushing on gloss retention and surface roughness of five bulk-fill resin composites. J. Esthet. Restor. Dent. 2018, 30, 59-69. [CrossRef]

20. Bociong, K.; Szczesio, A.; Sokolowski, K.; Domarecka, M.; Sokolowski, J.; Krasowski, M.; Lukomska-Szymanska, M. The influence of water sorption of dental light-cured composites on shrinkage stress. Materials 2017, 10, 1142. [CrossRef]

21. ISO. ISO 10993-12:2012. Biological Evaluation of Medical Devices_Part 12: Sample Preparation and Reference Materials; Advancement of Medical Instrumentation (AAMI): Arlington, VA, USA, 2012.

22. Pop, L.C.; Sfaelou, S.; Lianos, P. Cation adsorption by mesoporoustitaniaphotoanodes and its effect on the current-voltage characteristics of photoelectrochemical cells. Electrochim. Acta 2015, 156, 223-227. [CrossRef]

23. Pop, L.C.; Sygellou, L.; Dracopoulos, V.; Andrikopoulos, K.S.; Sfaeloua, S.; Lianos, P. One-step electrodeposition of CdSe on nanoparticulatetitaniafilmsand their use as sensitized photoanodes for photoelectrochemicalhydrogen production. Catal. Today 2015, 252, 157-161. [CrossRef]

24. Barbieri, G.M.; Mota, E.G.; Rodrigues-Junior, S.A.; Burnett, L.H., Jr. Effect of whitening dentifrices on the surface roughness of commercial composites. J. Esthet. Restor. Dent. 2011, 23, 338-345. [CrossRef] [PubMed]

25. Turssi, C.P.; De MoraesPurquerio, B.; Serra, M.C. Wear of dental resin composites: Insights into underlying processes and assessment methods-A review. J. Biomed. Mater. Res. B Appl. Biomater. 2003, 65, 280-285. [CrossRef]

26. Atai, M.; Yassini, E.; Amini, M.; Watts, D.C. The effect of a leucite-containing ceramic filler on the abrasive wear of dental composites. Dent. Mater. 2007, 23, 1181-1187. [CrossRef]

27. Carretero, V.; Giner-Tarrida, L.; Peñate, L.; Arregui, M. Shear bond strength of nanohybrid composite to biodentine with three different adhesives. Coatings 2019, 9, 783. [CrossRef]

28. Dietschi, D.; Campanile, G.; Holz, J.; Meyer, J.M. Comparison of the color stability of ten new-generation composites: An in vitro study. Dent. Mater. 1994, 10, 353-362. [CrossRef]

29. Malavasi, C.V.; Macedo, E.M.; SouzaKda, C.; Rego, G.F.; Schneider, L.F.; Cavalcante, L.M. Surface texture and optical properties of self-adhering composite materials after toothbrush abrasion. J. Contemp. Dent. Pract. 2015, 16, 775-782. [CrossRef]

30. Turssi, C.P.; Saad, J.R.; Duarte, S.L., Jr.; Rodrigues, A.L., Jr. Composite surfaces after finishing and polishing techniques. Am. J. Dent. 2000, 13, 136-138.

31. Ryba, T.M.; Dunn, W.J.; Murchinson, D.F. Surface roughness of various packable composites. Op. Dent. 2002, 27, 243-247.

32. Kanter, J.; Koski, R.E.; Martin, D. The relationship of weight loss to surface roughness of composite resins from simulated toothbrushing. J. Prosthet. Dent. 1982, 47, 505-513. [CrossRef]

33. Da Costa, J.; Adams-Belusko, A.; Riley, K.; Ferracane, J.L. The effect of various dentifrices on surface roughness and gloss of resin composites. J. Dent. 2010, 38, 123-128. [CrossRef] [PubMed] 
34. De Moraes, R.R.; dos Santos Ribeiro, D.; Klumb, M.M.; Cunha Brandt, W.; Correr-Sobrinho, L.; Bueno, M. In vitro toothbrushing abrasion of dental resin composites: Packable, microhybrid, nanohybrid and microfilled materials. Braz. Oral Res. 2008, 22, 112-118.

35. Borges, A.B.; Marsilio, A.L.; Pagani, C.; Rodrigues, J.R. Surface roughness of packable composite resins polished with various systems. J. Esthet. Restor. Dent. 2004, 16, 42-47. [CrossRef]

36. Kakaboura, A.; Fragouli, M.; Rahiotis, C.; Silikas, N. Evaluation of surface characteristics of dental composites using profilometry, scanning electron, atomic force microscopy and gloss-meter. J. Mater. Sci. Mater. Med. 2007, 18, 155-163. [CrossRef]

37. Carlen, A.; Nikdel, K.; Wennerberg, A.; Holmberg, K.; Olsson, J. Surface characteristics and in vitro biofilm formation on glass ionomer and composite resin. Biomaterials 2001, 22, 481-487. [CrossRef]

38. Quirynen, M.; Bollen, C.M. The influence of surface roughness and surface-free energy on supra- and subgingival plaque formation in man. A review of the literature. J. Clin. Periodontol. 1995, 22, 1-14. [CrossRef]

39. Mei, L.; Busscher, H.J.; van der Mei, H.C.; Ren, Y. Influence of surface roughness on streptococcal adhesion forces to composite resins. Dent. Mater. 2011, 27, 770-778. [CrossRef]

40. Wongpraparatana, I.; Matangkasombut, O.; Thanyasrisung, P.; Panich, M. Effect of vital tooth bleaching on surface roughness and streptococcal biofilm formation on direct tooth-colored restorative materials. $\mathrm{Op}$. Dent. 2018, 43, 51-59. [CrossRef]

41. Bollen, C.M.; Lambrechts, P.; Quirynen, M. Comparison of surface roughness of oral hard materials to the threshold surface roughness for bacterial plaque retention: A review of the literature. Dent. Mater. 1997, 13, 258-269. [CrossRef]

42. Rodrigues, S.A., Jr.; Scherrer, S.S.; Ferracane, J.L.; Della Bona, A. Microstructural characterization and fracture behavior of a microhybrid and a nanofill composite. Dent. Mater. 2008, 24, 1281-1288. [CrossRef] [PubMed]

43. Wilson, K.S.; Zhang, K.; Antonucci, J.M. Systematic variation of interfacial phase reactivity in dental nanocomposites. Biomaterials 2005, 26, 5095-5103. [CrossRef] [PubMed]

44. Ferracane, J.L. Hygroscopic and hydrolytic effects in dental polymer networks. Dent. Mater. 2006, 22, 211-222. [CrossRef] [PubMed]

45. Bagheri, R.; Tyas, M.J.; Burrow, M.F. Subsurface degradation of resinbased composites. Dent. Mater. 2007, 23, 944-951. [CrossRef] [PubMed]

46. Jin, J.; Takahashi, R.; Hickel, R.; Kunzelmann, K.H. Surface properties of universal and flowablenanohybrid composites after simulated tooth brushing. Am. J. Dent. 2014, 27, 149-154. [PubMed]

47. Abuna, G.; Feitosa, V.P.; Correr, A.B.; Cama, G.; Giannini, M.; Sinhoreti, M.A.; Pashley, D.H.; Sauro, S. Bonding performance of experimental bioactive/biomimetic self-etch adhesives doped with calciumphosphate fillers and biomimetic analogs of phosphoproteins. J. Dent. 2016, 52, 79-86. [CrossRef]

48. Berger, S.B.; Palialol, A.R.; Cavalli, V.; Giannini, M. Characterization of water sorption, solubility and filler particles of light-cured composite resins. Braz. Dent. J. 2009, 20, 314-318. [CrossRef]

49. Van Landuyt, K.L.; Nawrot, T.; Geebelen, B.; De Munck, J.; Snauwaert, J.; Yoshihara, K.; Scheers, H.; Godderis, L.; Hoet, P.; Van Meerbeek, B. How much do resin-based dental materials release? A meta-analytical approach. Dent. Mater. 2011, 27, 723-747. [CrossRef]

50. Gouveia, Z.; Perinpanayagam, H.; Zhu, J. Development of robust chitosan-silica class II hybrid coatings with antimicrobial properties for titanium implants. Coatings 2020, 10, 534. [CrossRef]

(C) 2020 by the authors. Licensee MDPI, Basel, Switzerland. This article is an open access article distributed under the terms and conditions of the Creative Commons Attribution (CC BY) license (http://creativecommons.org/licenses/by/4.0/). 